\title{
CORRELAÇÃO SISMOESTRATIGRÁFICA ENTRE AS BACIAS DO RECÔNCAVO E DE CAMAMU
}

\author{
SEISMOSTRATIGRAPHYC CORRELATION BETWEEN RECÔNCAVO AND CAMAMU BASINS
}

\section{Daniel Bono Ribeiro VILAS BOAS ${ }^{1}$, Paulo Augusto Vidigal Duarte SOUZA ${ }^{1}$, Michael HOLZ ${ }^{2}$}

${ }^{1}$ Grupo de Estratigrafia Teórica e Aplicada da Universidade Federal da Bahia (GETA-UFBA). Email: danielgeof@hotmail.com; paulo.augusto@ufba.br

²Departamento de Geofísica do Instituto de Geociências da Universidade Federal da Bahia. Email: michael@cpgg.ufba.br

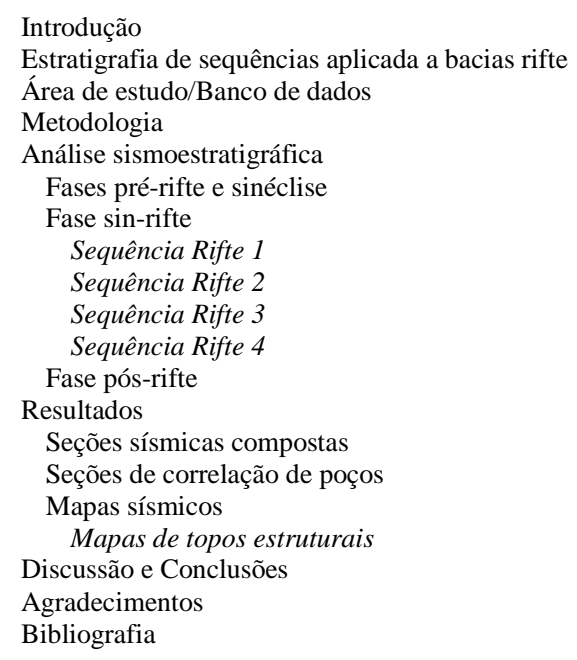

RESUMO - O trabalho consiste na interpretação de dados sísmicos 2D pós-empilhados de uma área compreendida entre o sul da Bacia do Recôncavo e o noroeste da Bacia de Camamu, auxiliada pela análise de perfis geofísicos de poços. A interpretação utilizou os princípios da estratigrafia de sequências aplicada a bacias do tipo rifte, à qual considera o tectonismo o principal mecanismo controlador da acomodação sedimentar, onde foram mapeadas as superfícies estratigráficas que compõem a seção sin-rifte das bacias em estudo, e assim, atribuídos os seus tratos de sistemas tectônicos. A metodologia do trabalho contemplou a confecção de sismogramas sintéticos de dados de poços para correlação com as linhas sísmicas, além da utilização de atributos sísmicos, úteis na identificação de terminações estratais, superfícies estratigráficas e feições estruturais, como falhas e superfície do embasamento. O mapeamento estratigráfico considerou discordâncias internas à supersequência rifte das bacias, segmentando-a em sequências de terceira ordem, o que evidencia o caráter episódico do tectonismo sofrido pelas bacias durante o período de rifteamento. Os resultados da interpretação permitiram a confecção de mapas e seções geológicas, de maneira a ilustrar os principais sistemas sedimentares atuantes em cada estágio do rifteamento das bacias, de acordo com seus respectivos tratos tectônicos interpretados.

Palavras-chave: Sismoestratigrafia, Recôncavo, Camamu, Falha da Barra, rifte.

ABSTRACT - This work consists in the interpretation of post-stacked 2D seismic data from an area between the south of Recôncavo basin and the north of Camamu basin, aided by the analysis of geophysical well logs. The interpretation used the principles of sequences stratigraphy applied to rift basins, which considers the tectonics as the main controller of accommodation space. The main stratigraphic surfaces that composes the syn-rift section of the basins were mapped, and, thus, assigned their tectonics tract systems. The methodology included the production of synthetic seismograms of well data for seismic correlation, besides the use of seismic attributes useful to identify strata terminations, stratigraphic surfaces and structural features such as faults and the top of the basement. The stratigraphic mapping considered internal unconformities to rift supersequence, segmenting it into third-order sequences, which shows the episodic character of tectonics suffered by the basins during the rifting period. The results of interpretation allowed produce maps and geological sections, in order to illustrate the main sedimentary systems operating in each rift stage of the basins, according to their respective interpreted tectonic tract.

Keywords: Seismic stratigraphy, Recôncavo, Camamu, Barra Fault, rift.

\section{INTRODUÇÃO}

As bacias do Recôncavo e de Camamu apresentam comprovado potencial petrolífero associado às suas seções rifte, contudo, a continuidade estatal entre as bacias ainda carece de estudos.

O presente trabalho tem como principal objetivo a interpretação sísmica da região do contato entre as bacias do Recôncavo e de
Camamu, correlacionando-se os depósitos entre as bacias, especialmente em suas seções sinrifte. Para tanto, seguiu-se os princípios da estratigrafia de sequências aplicada a bacias rifte, inicialmente preconizada por Prosser (1993), que elaborou uma adaptação ao modelo da estratigrafia de sequências clássico.

A Bacia do Recôncavo está inserida no 
aulacógeno Recôncavo-Tucano-Jatobá, ou seja, constitui um rifte intracontinental que foi abortado; enquanto que a Bacia de Camamu constitui uma das bacias de margem leste brasileira.

\section{ESTRATIGRAFIA DE SEQUÊNCIAS APLICADA A BACIAS RIFTE}

A ferramenta da estratigrafia de sequências, embasada nos conceitos da estratigrafia clássica, apresenta grande sucesso na interpretação sísmica em bacias sedimentares (Posamentier \& Vail, 1988), sobretudo nas bacias brasileiras de margem passiva. Contudo, sua aplicação em modelos de bacias do tipo rifte, necessitam de algumas adaptações. Prosser (1993) introduziu tal adaptação para bacias rifte, considerando que o principal mecanismo controlador da sedimentação anteriormente sendo as variações do nível de base, agora passa a ser o tectonismo associado ao rifteamento. Holz et al. (2014), embasado estratigráficas chaves, é mostrado na figura 1.
Ambas foram formadas sob o contexto da Junção Tríplice de Salvador, e apresentam alta correlação estratigráfica, sobretudo entre suas fases pré-rifte e sin-rifte (Caixeta et al., 2007; Ferreira et al., 2009; Silva et al., 2007).

nos trabalhos de Gawthorpe \& Leeder (2000) sobre a formação de sistemas rifte, modificou alguns aspectos do modelo estratigráfico de Prosser (1993), propondo os chamados tratos de sistemas tectônicos, sendo eles de início (TTIR), desenvolvimento (TTDR), e final de rifte (TTFR), limitados entre a superfície de início de desenvolvimento de rifte (SIDR), a superfície de máximo rifteamento (SMR), e as discordâncias entre as sequências deposicionais. O modelo usado no presente trabalho (apud Holz et al., 2015), com seus tratos de sistemas tectônicos e superfícies

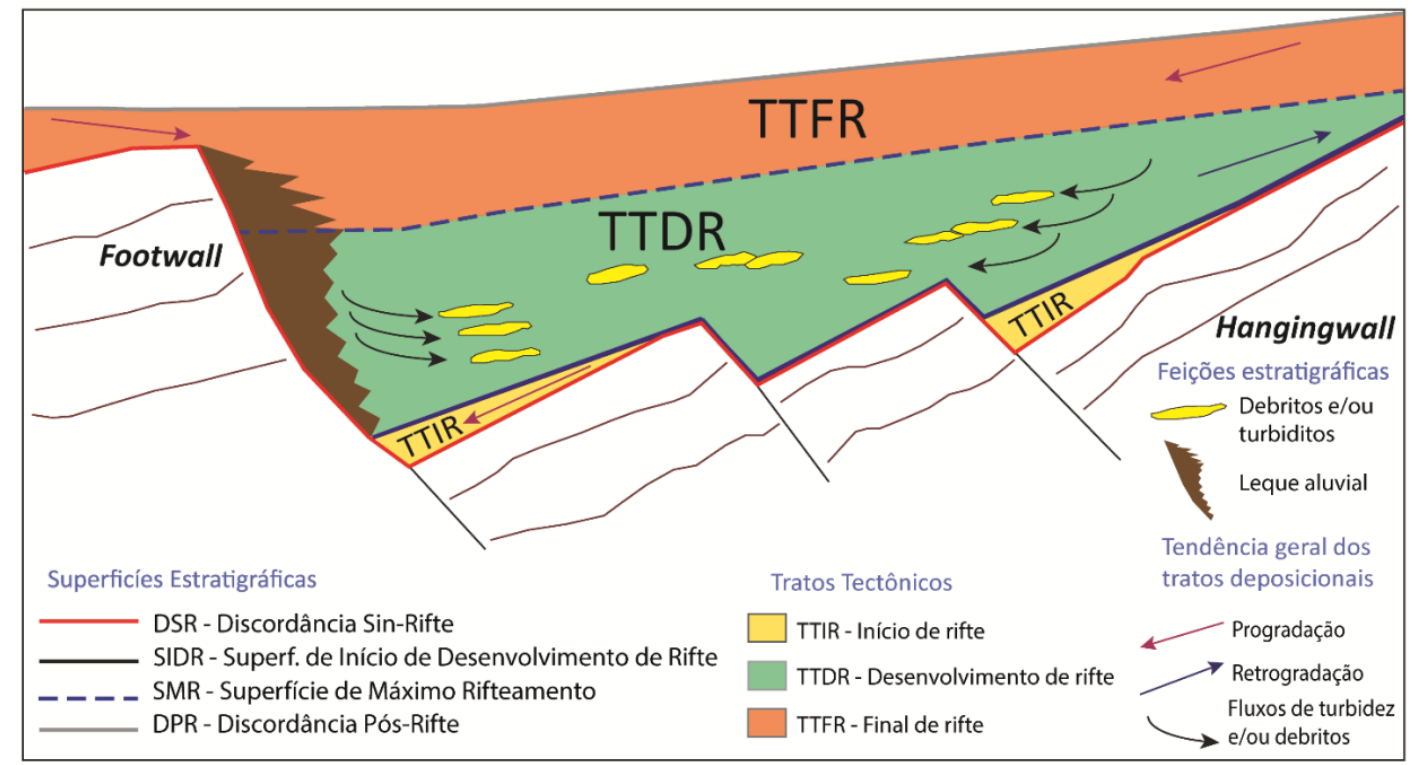

Figura 1 - Modelo estratigráfico para um sistema de meio-gráben de bacia rifte, modificado de Holz et al. (2015). Notar as superfícies-chaves e os três tratos deposicionais.

\section{ÁREA DE ESTUDO / BANCO DE DADOS}

Os dados sísmicos e de poços disponíveis para o estudo integram o banco de dados do projeto de P\&D GP-03 financiado pela empresa GEOPARK e denominado Projeto RECAMU (Análise geológica comparativa da fase rifte da Bacia de Camamu e da Bacia do Recôncavo).
Foram utilizados 140 linhas sísmicas pósempilhadas e dados de 27 poços, todos eles sobre a área de estudo que compõe a porção sul da Bacia do Recôncavo e noroeste da Bacia de Camamu, dispostos como mostra o mapa da figura 2.

\section{METODOLOGIA}

Desenvolveu-se as etapas convencionais de uma interpretação sismoestratigráfica, tendo sido utilizado principalmente os softwares de interpretação sísmica IHS Kingdom, auxiliado pelo OpendTect. Os perfis geofísicos de poços, especialmente os de raios gama, foram interpretados sob a óptica da estratigrafia de sequências aplicada a bacias do tipo rifte. 


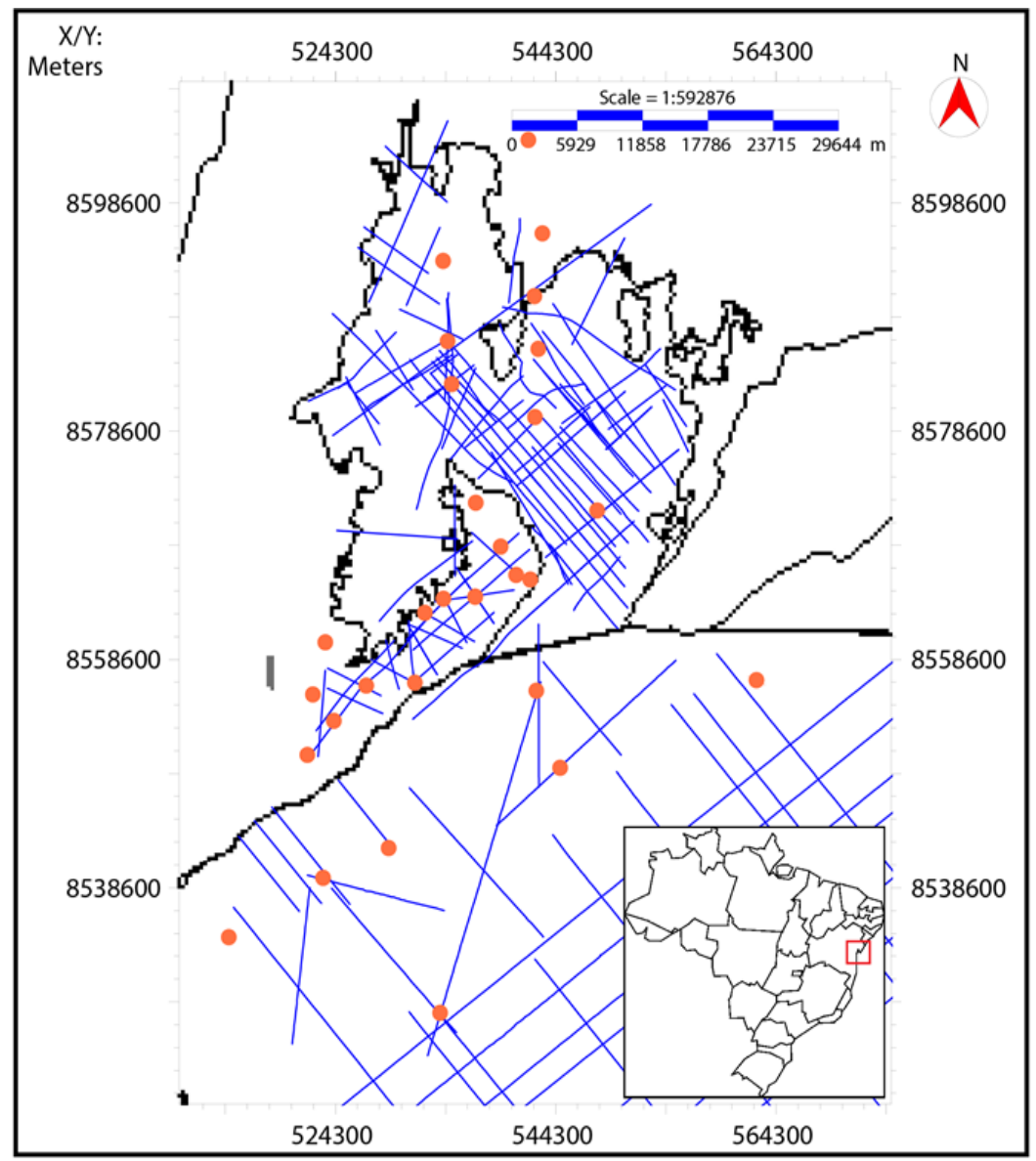

Figura 2 - Linhas sísmicas (em azul) e poços (em laranja) disponíveis, inseridos na área de estudo; região de contato entre as bacias do Recôncavo e de Camamu (nordeste do Brasil).

A interpretação sismoestratigráfica foi partir das curvas de densidade e sônico. auxiliada pela análise de atributos sísmicos do traço complexo, como amplitude, fase e frequência instantâneas (Payton, 1977), os quais foram úteis na identificação de terminações estratais e continuidades de refletores. O TecVA (Técnica Volume de Amplitudes, ou pseudo-relief; Santos \& Amorim, 2005) foi fundamental no mapeamento estrutural do topo do embasamento e das principais falhas nas seções.

Os atributos citados foram computados a partir de ferramenta calculadora disponível pelo software IHS Kingdom, e podem ser visualizados na figura 3.

Para correlação entre os dados sísmicos e de poços, foram gerados sismogramas sintéticos a

Um exemplo de amarração sísmica-poço pode ser visualizado através do painel de correlação do traço sintético com os traços registrados, e do posicionamento resultante do poço na seção, exibidos na figura 4.

Dados culturais retirados da literatura das bacias estudadas foram também úteis na interpretação, especialmente mapas gravimétricos e estruturais dos trabalhos de Ferreira et al. (2009), Destro et al. (2003) e Amaral (2009).

As superfícies demarcadas na interpretação possibilitaram a confecção de mapas e seções geológicas, ilustrando a disposição das camadas em subsuperfície da região estudada, esquematizando a correlação entre os depósitos sin-rifte das bacias.

\section{ANÁLISE SISMOESTRATIGRÁFICA}

Foram interpretadas sequências de terceira ordem, onde os depósitos das fases sinéclise, pré-rifte e sin-rifte foram, correlacionáveis cronoestratigraficamente entre as bacias do Recôncavo e de Camamu.

Feições estruturais como a Falha da Barra atravessam a seção rifte entre as bacias; contudo, não as diferencia em seu caráter genético. Um resumo da interpretação realizada pode ser visualizado através da correlação com a carta de Silva et al. (2007) para a Bacia do Recôncavo (Figura 5). 


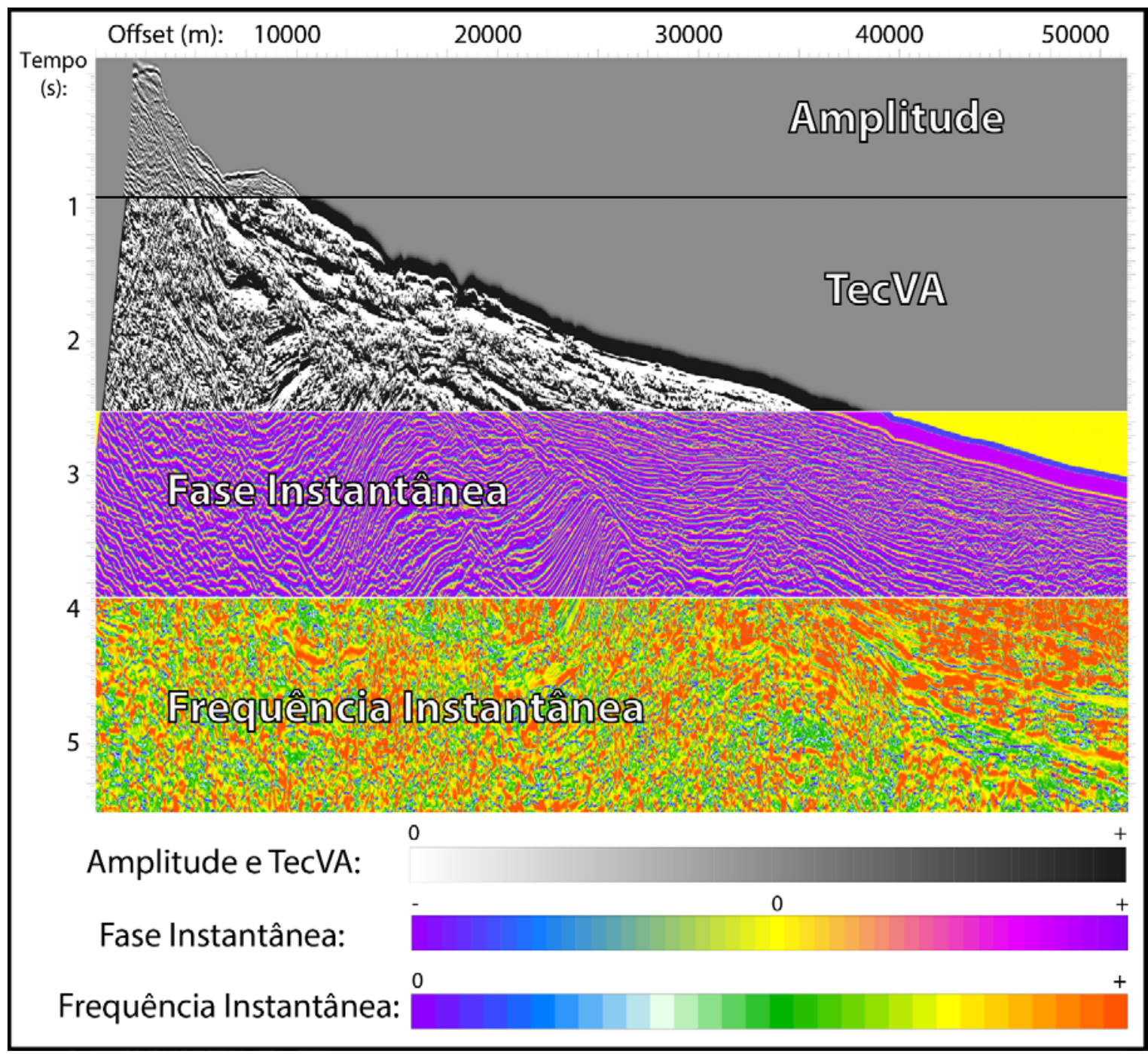

Figura 3. Atributos sísmicos calculados e plotados em seção no software IHS Kingdom (amplitude, TecVA,fase e frequência instantâneas).

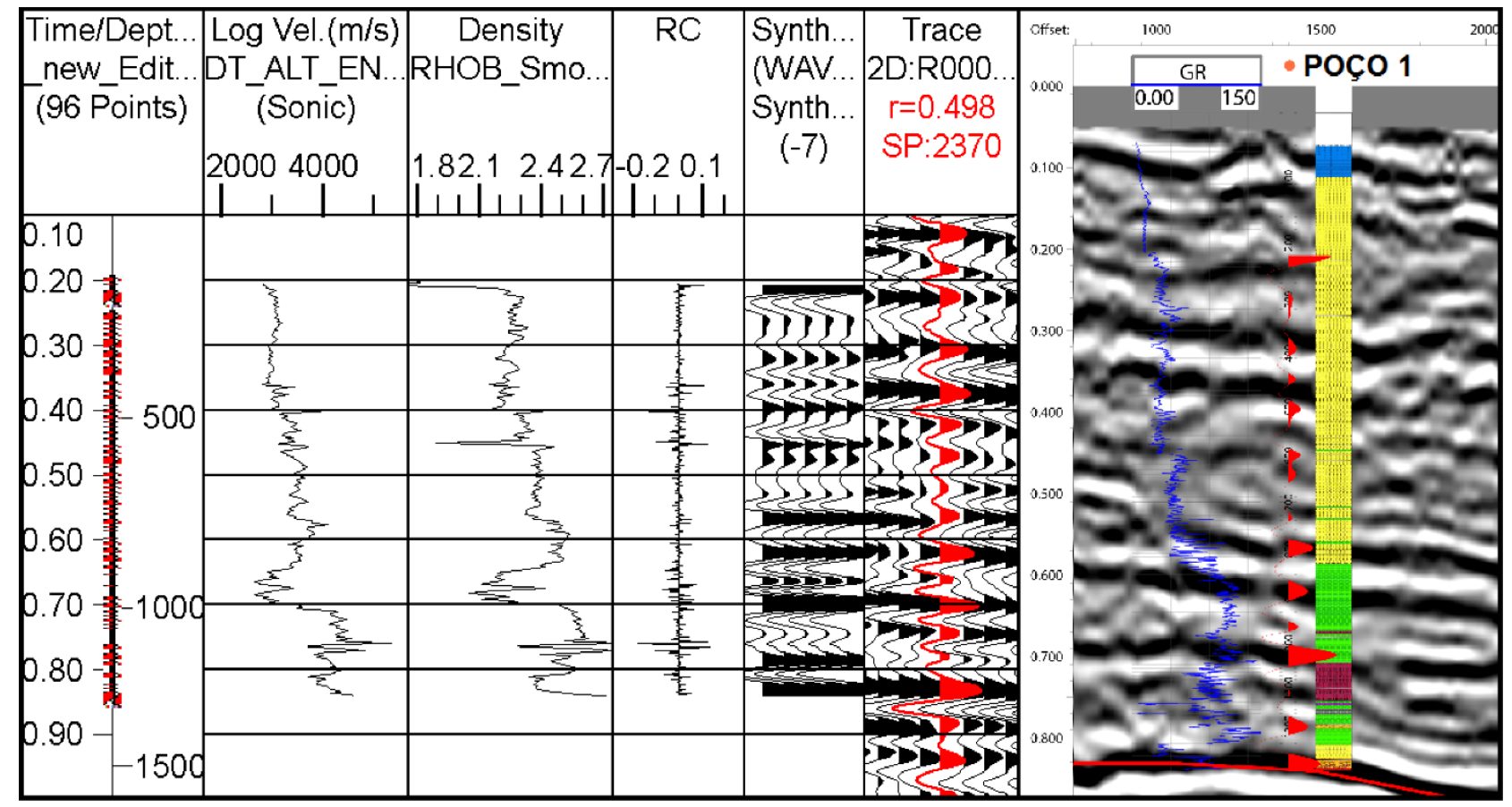

Figura 4 - Painel de correlação sísmica-poço, e a amarração resultante na seção sísmica. Notar a excelente correspondência entre traços sísmicos e camadas-guias no poço. 


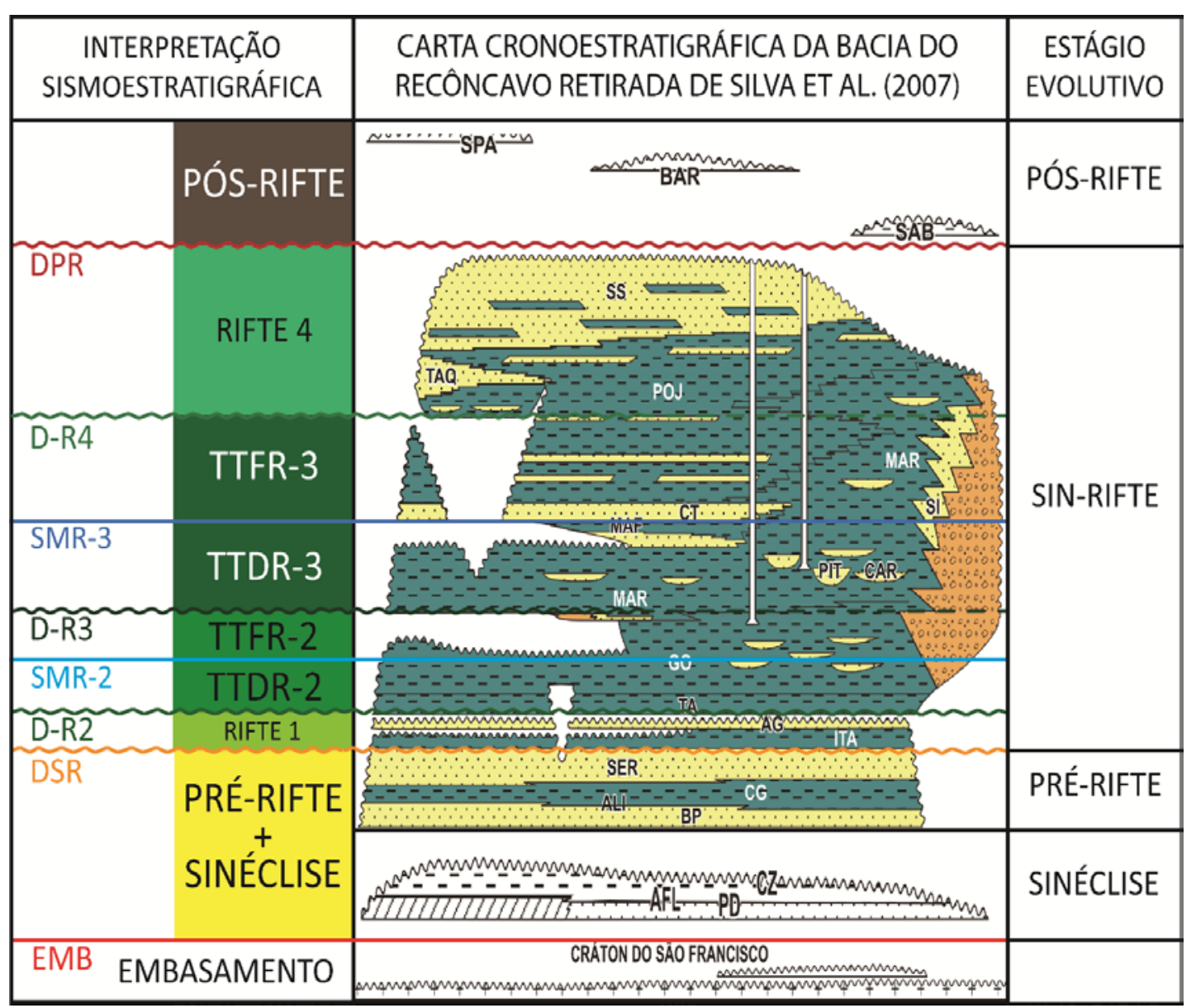

Figura 5 - Interpretação estratigráfica sobre o modelo cronoestratigráfico da Bacia do Recôncavo, extraído de Silva et al. (2007).

\section{Fases pré-rifte e sinéclise}

Os primeiros depósitos interpretados, representam as fases sinéclise (ao longo do período Permiano) e pré-rifte das bacias, apresentadas na seção por um padrão de refletores plano-paralelos com boa continuidade, limitadas na base pelo embasamento (EMB) e ao topo pela discordância sin-rifte (DSR).

A sequência assume espessura sísmica aproximadamente constante por toda a área de estudo, em torno de 600 ms (vide Figura 11A). A análise dos dados de poços foi fundamental na determinação da DSR, marcada no topo do padrão caixa e de baixo valor da curva de raios gama, correlato com a Formação Sergi, segundo a litoestratigrafia.

\section{Fase sin-rifte}

Dentro da supersequência sin-rifte das bacias, foram mapeadas três discordâncias, diferenciando o rifte em quatro sequências deposicionais, chamadas de: Rifte 1, Rifte 2, Rifte 3 e Rifte 4.

O padrão de amplitudes é variável ao longo do rifte, apresentando um caráter predominantemente progradacional nos seus primeiros depósitos, principalmente em suas porções proximais; e posteriormente um padrão plano-paralelo de baixa amplitude e continuidade, especialmente indo em direção aos depocentros.

Em termos estruturais, o mapeamento sísmico contemplou uma série de falhas normais de alto ângulo, sintéticas e antitéticas, de direção preferencial NE-SW, atravessando os depósitos sin-rifte das bacias.

\section{Sequência Rifte 1}

A sequência Rifte 1 representa os primeiros depósitos da fase sin-rifte (sobreposto à DSR), originados em um ambiente lacustre inicial, predominantemente raso.

Sismicamente apresentam refletores de alta amplitude e continuidade, com espessuras sísmicas em torno de $100 \mathrm{~ms}$, que podem aumentar em direção às regiões mais profundas, indicando o contexto rifte ao qual a sequência foi formada.

A aplicação da estratigrafia de sequências para bacias rifte para a sequência Rifte 1 , só foi permitida através da análise dos perfis 
geofísicos de poços (vide Figura 6), devido à limitação quanto a resolução sísmica disponível, considerando as baixas espessuras da camada.

Os dados de poços permitiram a identificação de uma superfície de início de desenvolvimento de rifte (SIDR-1), ao qual marca a passagem de um padrão progradacional para retrogradacional, marcado por um aumento do GR, ainda no início da fase rifte.

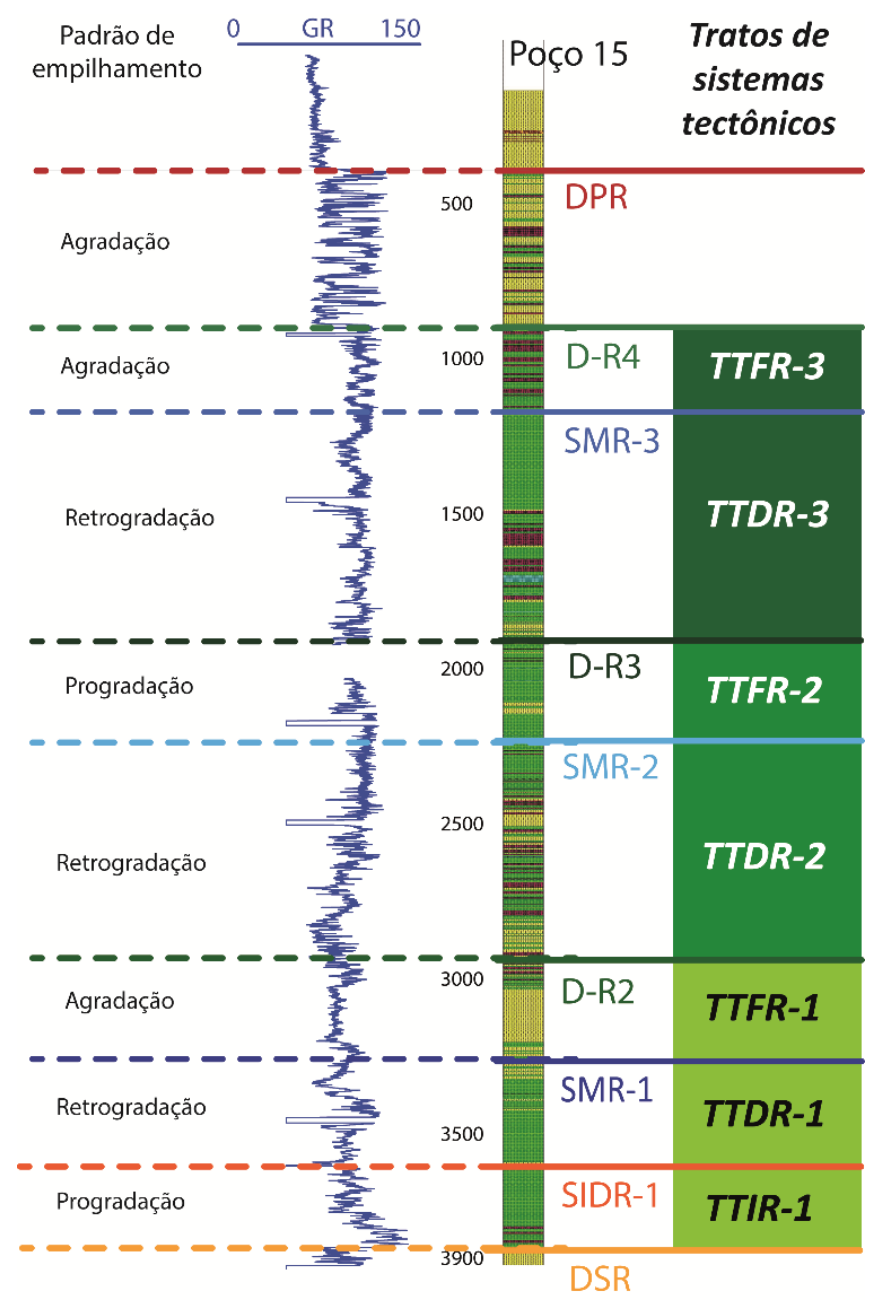

Figura 6. Interpretação estratigráfica de um poço localizado na porção noroeste da Bacia de Camamu, evidenciando os tratos tectônicos de início (TTIR), desenvolvimento (TTDR) e final (TTFR) de rifte para as três primeiras sequências da fase sin-rifte

Com isto, a SIDR-1 limita ao topo o trato tectônico de início de rifte da primeira sequência (TTIR-1), caracterizado por grande influência flúvio-deltaica vindo das margens, sendo muitas vezes correlacionada às formações Itaparica e Água Grande, segundo as descrições litoestratigráficas dos poços.

A superfície de máximo rifteamento da primeira sequência (SMR-1) foi identificada apenas nos poços próximos aos depocentros da bacia, indicando que tenha sido erodida nas regiões proximais. A SMR-1 divide então a sequência nos tratos TTDR-1 e TTFR-1

\section{Sequência Rifte 2}

Sotoposto à D-R2 e sobreposto à D-R3, a sequência Rifte 2 está presente em todas as seções analisadas nesta área, assumindo uma espessura sísmica entre $200 \mathrm{~ms}$ e $500 \mathrm{~ms}$ na região sul da Bacia do Recôncavo, e 300 ms a 1 s no noroeste da Bacia de Camamu.

Como característica marcante em todas as seções da fase sin-rifte, esta sequência também apresenta espessamento em direção às falhas principais. Em critério de sismofácies, a sequência é marcada por um padrão de amplitudes levemente caótico e de baixa continuidade (como mostra a seção da Figura 7), que de maneira geral indica uma expansão no sistema lacustre.

A D-R3 foi interpretada por truncamentos evidentes apenas nas porções proximais, onde, próximo aos depocentros os refletores são mais paralelos e os truncamentos já não são mais evidentes, sendo assim, a discordância é seguida pela conformidade correlativa na região junto à borda falhada. 


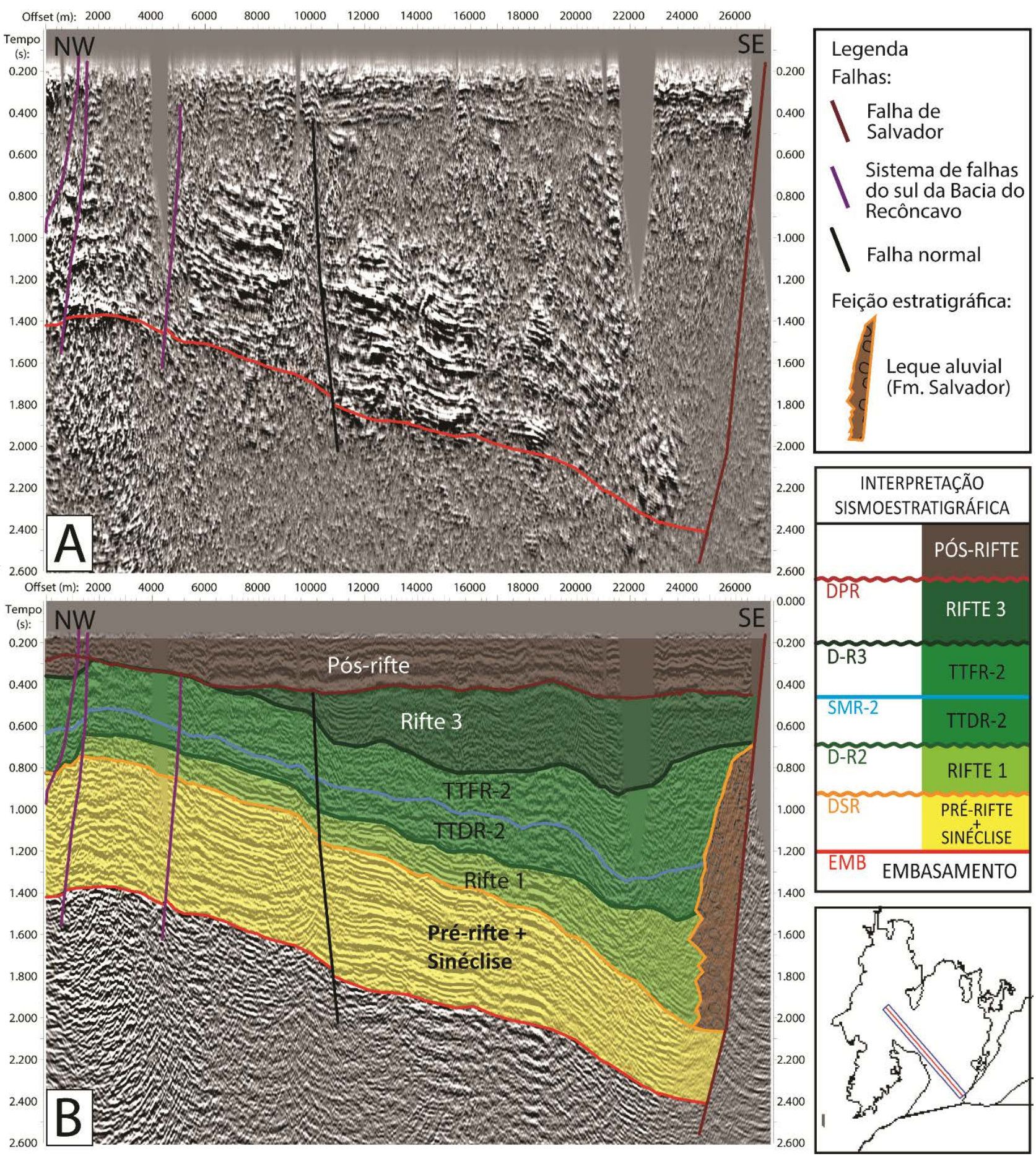

Figura 7. Seção sísmica dip da região sul da Bacia do Recôncavo: (A) com o atributo TecVA e interpretação estrutural; (B) em amplitude sobreposta à interpretação sismoestratigráfica.

Uma superfície com inúmeros downlaps mergulhando preferencialmente para sudeste foi identificada em diversas seções dips no intervalo da sequência Rifte 2, caracterizando uma sedimentação predominantemente vinda da margem flexural (oeste/noroeste do continente). Tal superfície de downlaps foi então interpretada como a superfície de máximo rifteamento, SMR-2, indicando o momento de maior expansão do sistema lacustre da sequência, segmentando-a assim nos tratos tectônicos de desenvolvimento (TTDR-2) e final (TTFR-2) de rifte (vide Figura 6).

A análise de poços dessa sequência também permitiu a identificação dos primeiros corpos arenosos como debritos e/ou turbiditos da fase sin-rifte, encontrados principalmente nas porções mais distais. Tais corpos são indicados por diminuição brusca da curva de raios gama, assumindo um padrão predominantemente agradacional a progradacional, especialmente dentro do contexto geral de expansão do sistema rifte. 


\section{Sequência Rifte 3}

Sotoposto à D-R3, a sequência Rifte 3 assume um padrão semelhante à sequência anterior, com refletores de baixas continuidade e amplitude resultante de um sistema lacustre profundo. A sequência possui como limite superior a D-R4, que também só apresenta truncamentos subjacentes nas porções mais próximas à margem flexural, e sua continuação em direção à borda falhada segue por uma conformidade correlativa (assim como a D-R3). Contudo, na região sul da Bacia do Recôncavo, o limite superior se torna a DPR (discordância pós-rifte), considerando a D-R4 apenas evidente ao sul do Sistema de Falhas da Barra, e em suas porções mais proximais, a sequência é ausente, tendo sido totalmente erodida ou nem depositada.

Através das seções presentes na região noroeste da Bacia de Camamu foi possível mapear uma superfície de downlaps interna à sequência Rifte 3 , configurando assim a SMR-3. Esta superfície foi confirmada apenas com a análise dos perfis geofísicos de poços, que indicavam uma mudança no padrão retrogradacional para progradacional (ou agradacional) do perfil de raios gama (vide Figura 9), onde nas seções sísmicas os downlaps encontrados eram menos evidentes (em virtude das baixas amplitudes e resoluções), se comparados com os da SMR2. Ainda assim, foi possível a identificação do mergulho preferencial para sudeste dos downlaps, ao qual dividiu a sequência em TTDR-3 e TTFR-3.

Assim como a sequência anterior, diversos corpos que indicavam fluxos gravitacionais arenosos, especialmente debritos, foram interpretados na análise dos dados de poços, sobretudo nas regiões mais profundas das bacias.

\section{Sequência Rifte 4}

A primeira diferença estratigráfica significativa entre as seções sin-rifte das bacias analisadas se dá na presença da D-R4 apenas na região da Bacia de Camamu, com isso, a última sequência sin-rifte, nomeada de Rifte 4, está presente somente na região ao sul do Sistema de Falhas da Barra, como pode ser visto nas seções compostas da figura 8 . Tal fato é um grande indício do interrompimento da subsidência mecânica associada ao tectonismo na região sul da Bacia do Recôncavo, enquanto que na porção da Bacia de Camamu ainda houve geração de espaço de acomodação o suficiente para deposição de, ao menos, mais uma sequência deposicional sin-rifte.

A sequência Rifte 4 apresenta suas maiores espessuras em um depocentro localizado junto ao Sistema de Falhas da Barra, atingindo em torno de $1,3 \mathrm{~s}$, como mostra o mapa da figura $11 \mathrm{G}$.

A sismofácies desta sequência se apresenta de maneira semelhante às duas últimas, característica de depósitos lacustres. Entretanto, algumas seções evidenciam maiores valores de amplitude se comparadas com os das outras sequências sin-rifte (vide Figura 8B). Este aspecto pode ser resultado de menores tempos de trânsito da onda, tendo sofrido menos perdas por dispersão ou atenuação, ou ainda, podem ser explicados por um aumento relativo das progradações flúvio-deltaicas vindas das margens, resultando em maiores contrastes de impedância acústica. A última explicação concorda com o modelo estratigráfico aplicado, corroborando com um contexto final de rifte, marcado por diminuição do tectonismo e predomínio de depósitos fluviais proximais em frente aos lacustres profundos.

\section{Fase pós-rifte}

Apenas evidente em algumas seções sísmicas na região sul da Bacia do Recôncavo, a DPR (discordância pós-rifte) se apresenta como uma extensa discordância angular que divide os depósitos do final da fase sin-rifte e os pós-rifteamento. A fase pós-rifte foi interpretada como uma única sequência sedimentar, marcada por refletores planoparalelos de alta amplitude.

Em virtude dos baixos tempos desta sequência nos sismogramas do sul da Bacia do Recôncavo, muitas seções apresentavam uma baixa qualidade no padrão de refletores, especialmente devido à Zona de Baixa Velocidade (ZBV) que atinge dados sísmicos terrestres. Tal fato, além da baixa resolução sísmica, leva a interpretação da DPR na região da Bacia do Recôncavo apenas confiável em algumas seções sísmicas (especialmente as marinhas). Contudo, a análise dos dados de 
poços nesta região permitiu sua interpretação com maior confiabilidade, especialmente devido à mudança na amostragem de calha de depósitos mais argilosos, flúvio-deltaicolacustres de coloração cinza ou verde, para camadas mais arenosas de cor esbranquiçada ou avermelhada, que repercutem em grande diminuição dos perfis de raios gama, sônico e resistividade (vide Figura 6). Os dados sísmicos marinhos da região noroeste da Bacia de Camamu permitiram um melhor mapeamento da discordância pós-rifte, apresentando grande mudança angular entre as camadas rifte e pós-rifteamento, sendo a última marcada por uma sismofácies de amplitude e continuidade alta. Os poços na região também auxiliaram na sua interpretação, onde seus depósitos acima comumente apresentam um pacote carbonático marinho restrito.

\section{Seções sísmicas compostas}

A fim de melhor correlação entre os depósitos das bacias investigadas, foram confeccionadas seções sísmicas compostas ilustradas na Figura 8. Estas, evidenciam o espessamento preferencial das sequências sinrifte em direção à Bacia de Camamu. A comparação entre as seções compostas permite observar a grande diferença de rejeito que ocorre dentro do Sistema de Falhas da Barra, consistindo de menos de 100 ms, na região da desembocadura da Baía de Todos os Santos (Figura 8A), até mais de $1,5 \mathrm{~s}$, sob a ilha de Itaparica (Figura 8B).

\section{Seções de correlação de poços}

Como síntese à interpretação dos dados de poços foram confeccionadas duas seções geológicas presentes na figura 9. Devido a escala vertical dada em metros, as seções estratigráficas de poços permitem uma análise em termos de profundidades e espessuras reais das camadas interpretadas. Assim como explanado na comparação entre as seções sísmicas compostas, as seções geológicas de poços também ilustram as diferenças de rejeitos do Sistema de Falhas da Barra.

\section{Mapas sísmicos}

Após a interpretação sismoestratigráfica realizada, foram confeccionados mapas de tempos de superfícies estratigráficas (Figura 10 ), e de espessura sísmica (Figura 11).

\section{Mapas de topos estruturais}

Através dos mapas da figura 10 é possível inferir a posição dos depocentros no momento de deposição de cada sequência (indicados pelas cores mais próximas ao violeta), além das principais falhas (regiões de alta convergência das curvas de nível) e seus rejeitos associados.

A comparação entre as figuras $10 \mathrm{~A}$ e $10 \mathrm{~B}$ permite observar que não há diferenças

\section{ADOS}

estruturais significativas entre o topo do embasamento e da discordância sin-rifte, corroborando com a característica planoparalela das camadas rochosas anteriores ao rifteamento dentro da área de estudo.

As figuras 10C, 10D e 10E ilustram o aprofundamento preferencial das superfícies no sentido sudeste, em direção à Falha de Salvador (na parte da Bacia do Recôncavo) e para as porções mais distais da Bacia de Camamu, designando o mergulho das duas primeiras sequências da fase sin-rifte (Rifte 1 e Rifte 2). Todavia, os mapas também indicam a presença de um depocentro localizado junto ao Sistema de Falhas da Barra na área da ilha de Itaparica, correspondente à área de maior rejeito do sistema de falhas. As duas últimas sequências da fase sin-rifte (Rifte 3 e Rifte 4) não foram mapeadas por toda a área de estudo, e isto pode ser observado através das figuras $10 \mathrm{E}, 10 \mathrm{~F}$ e 10G, onde o último mapa mostra que o limite entre as sequências (D-R4) foi encontrado apenas ao sul do Sistema de Falhas da Barra.

A discordância pós-rifte não apresenta grandes variações na área do Recôncavo-sul, tendo sido mapeada em baixos tempos, com um leve aprofundamento em direção à Falha de Salvador, margem leste da Bacia do Recôncavo (vide Figura 10H). Entretanto, no setor noroeste da Bacia de Camamu é notório a grande variação que ocorre na DPR ao sul do principal sistema de falhas, indo de menos de 200 ms nas porções marinhas mais rasas, até $2 \mathrm{~s}$ após 0 sistema. Isso não necessariamente reflete que a parte distal foi mais erodida, é preciso notar que o mapa está em tempo e além de maior subsidência na parte da Bacia de Camamu, já que esta evoluiu para drifte, tem maior lâmina d'água que acaba por aumentar o tempo de trânsito da onda sísmica. 

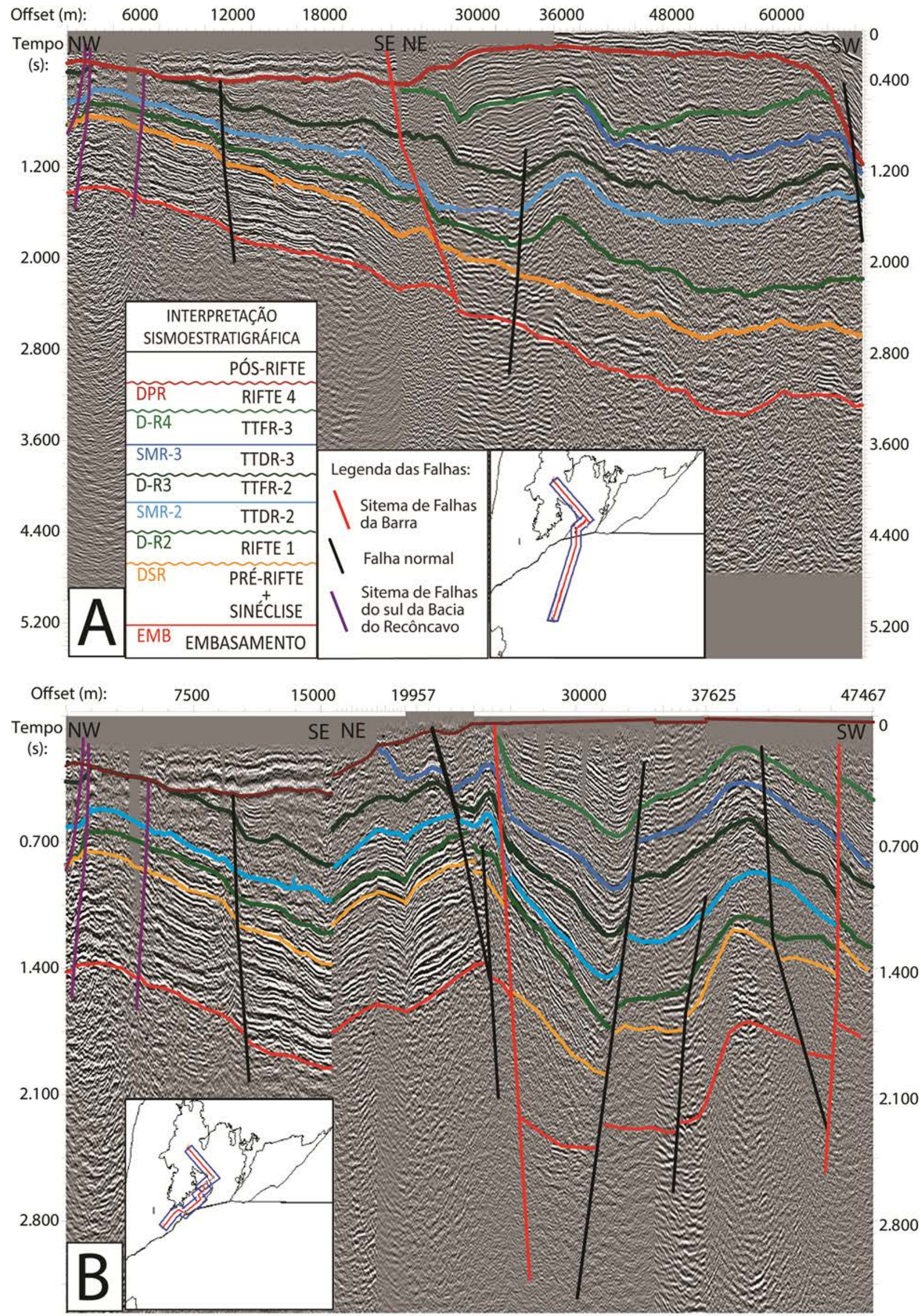

Figura 8. Seções sísmicas compostas interpretadas, de direção inicial NW-SE e posterior NE-SW, que ligam a porção sul da Bacia do Recôncavo com o setor noroeste da Bacia de Camamu: (A) atravessando a desembocadura da Baía de Todos os Santos; (B) compondo a região da ilha de Itaparica. 
Poço 10 Poço 11 Poço 12 Poço $13 \quad$ Poço 14 Poço $15 \quad$ Poço 16
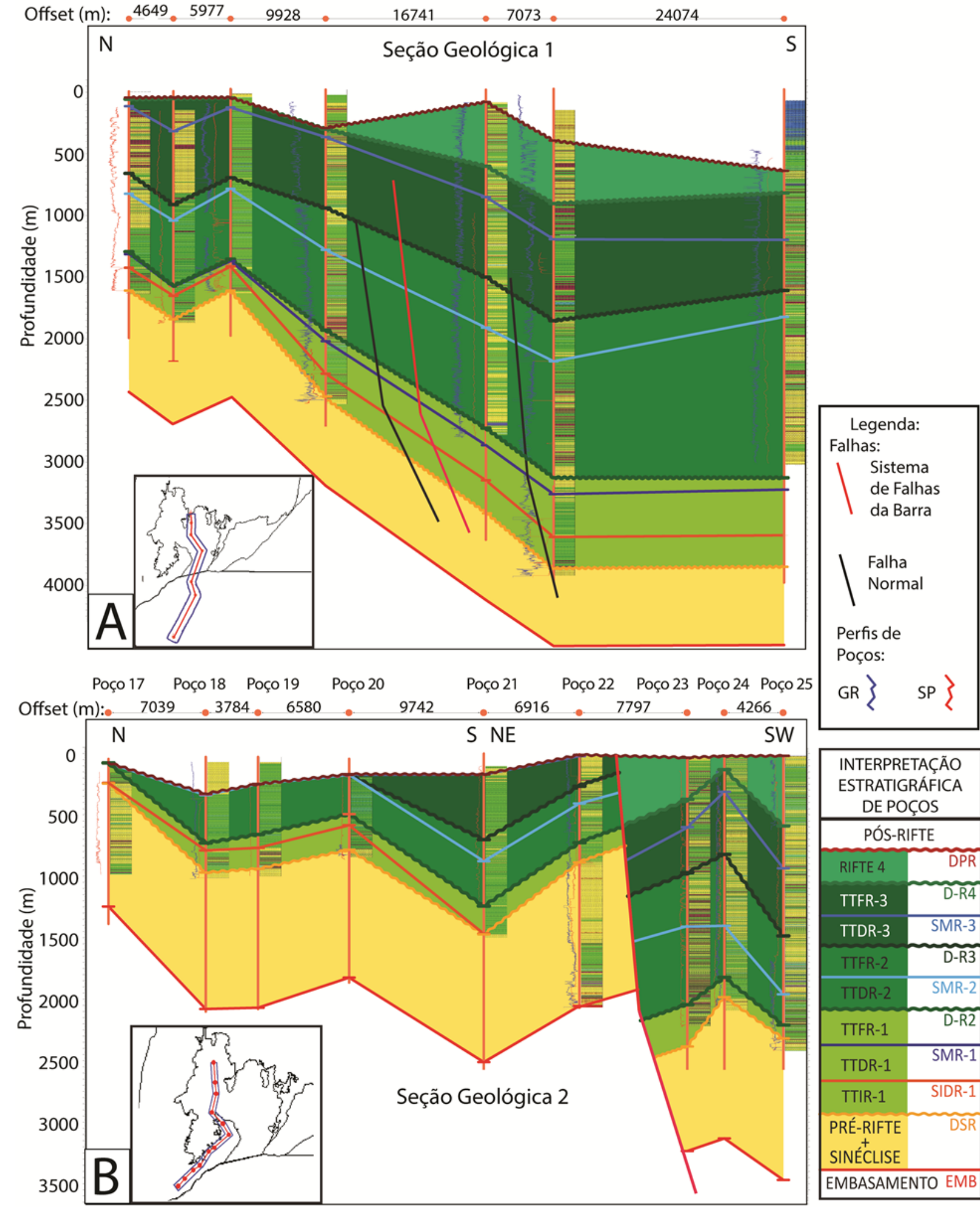

\begin{tabular}{|l|}
\hline $\begin{array}{l}\text { INTERPRETAÇÃO } \\
\text { ESTRATIGRÁFICA } \\
\text { DE POÇOS }\end{array}$ \\
\hline \multicolumn{1}{|c|}{ PÓS-RIFTE } \\
\hline RIFTE 4 \\
\hline TTFR-3
\end{tabular}

Figura 9 - Seções geológicas de correlação estratigráfica de poços, assumindo direção preferencial inicialmente N-S e posteriormente NE-SW, que ligam a porção sul da Bacia do Recôncavo com o setor noroeste da Bacia de Camamu: (A) atravessando a desembocadura da Baía de Todos os Santos; (B) compondo a região da ilha de Itaparica.

\section{Mapas de espessura sísmica}

O mapeamento estratigráfico também permitiu a confecção de mapas de intervalos de tempo das sequências sedimentares delimitadas (Figura 11).

Tais mapas são muito úteis na análise de espessura das camadas rochosas, permitindo assim, inferir a localização dos depocentros durante a deposição de cada sequência interpretada, os períodos de maior criação de espaço de acomodação, e ainda o sentido dos principais fluxos de sedimentação. 

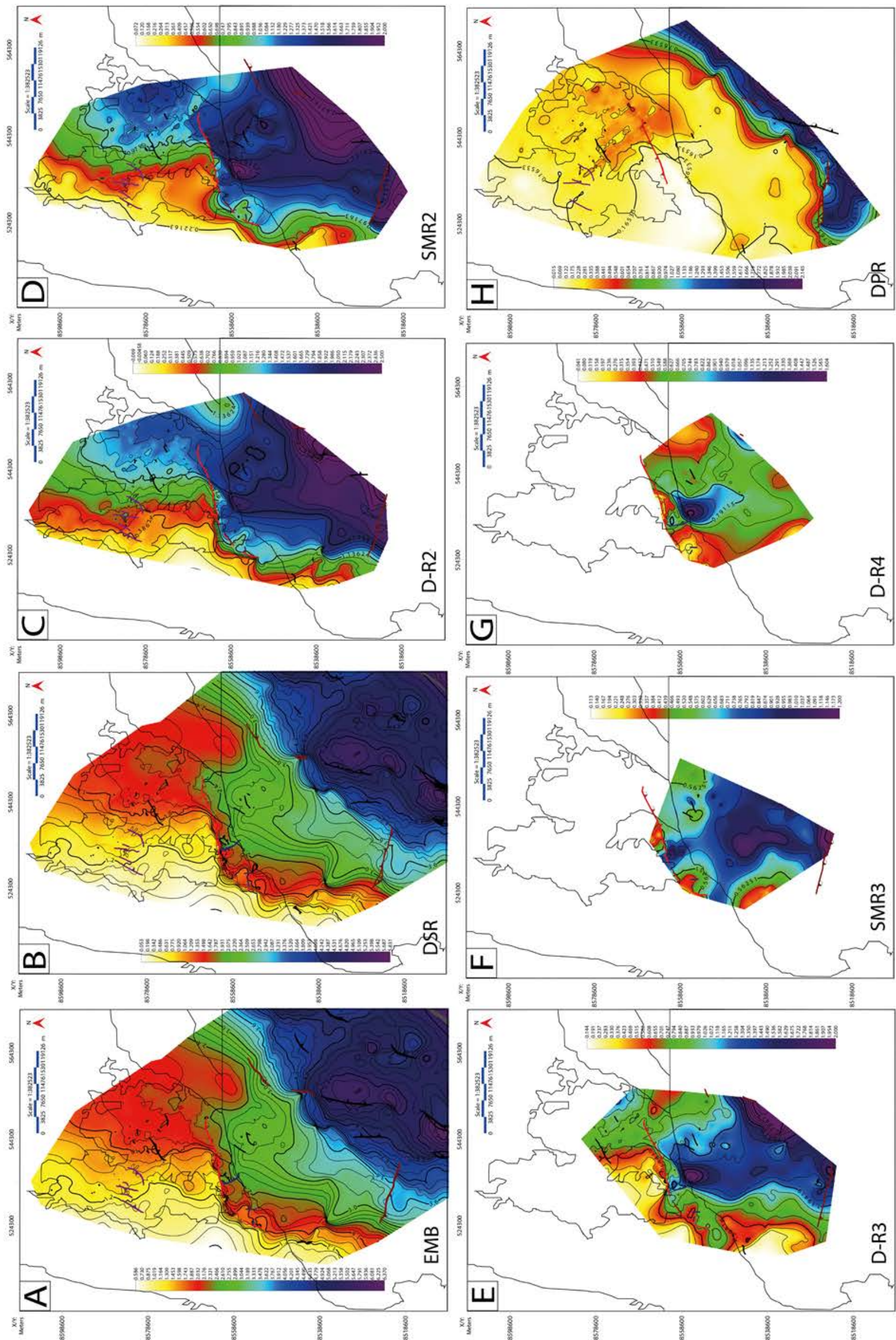

Figura 10 - Mapas de topo das superfícies estratigráficas interpretadas na área sul da Bacia do Recôncavo e norte da Bacia de Camamu: A) embasamento; B) discordância sin-rifte; C) D-R2; D) SMR-2; E) D-R3; F) SMR-3; G) D-R4; H) discordância pós-rifte. 

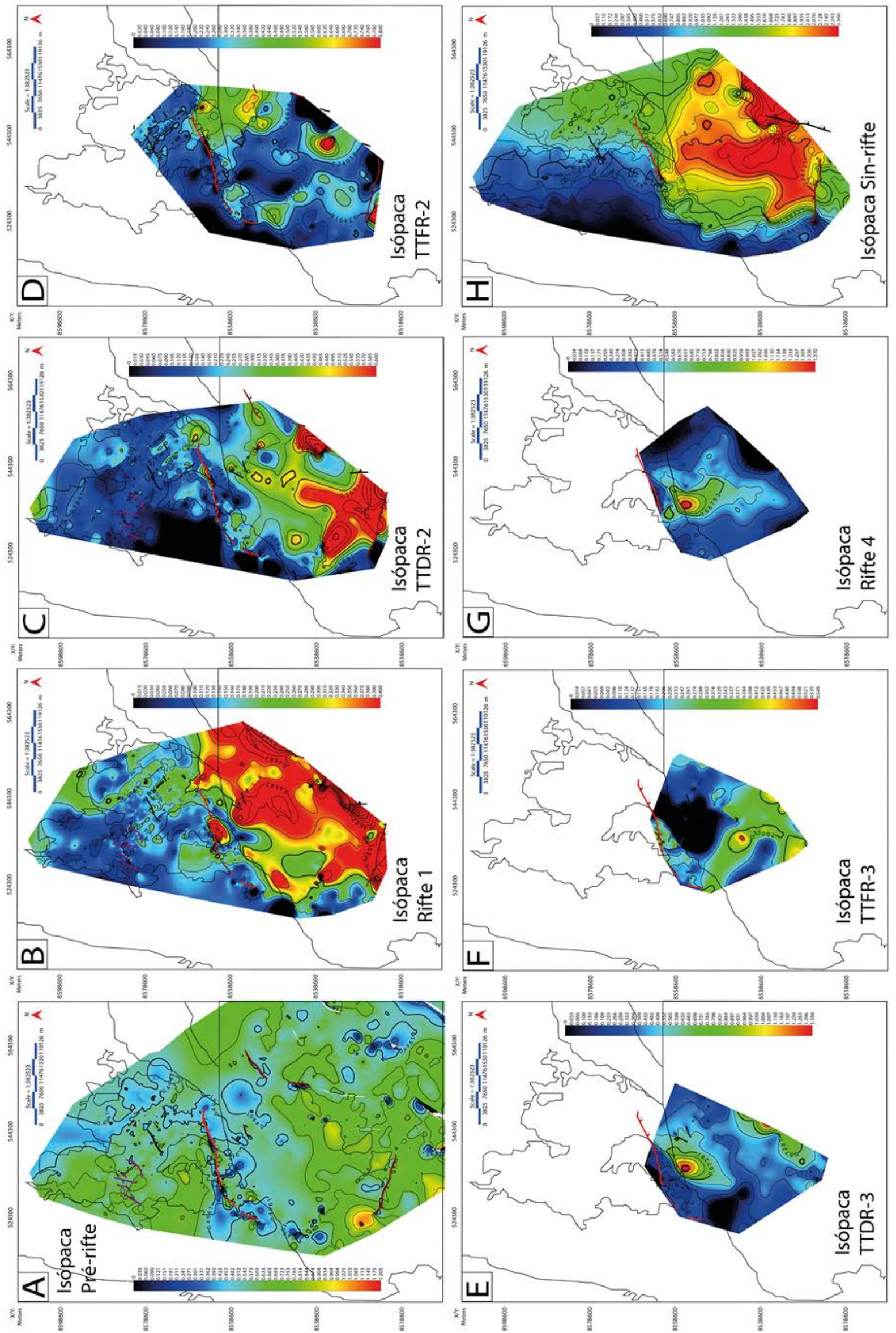

Figura 11 - Mapas de espessura sísmicas das sequências e tratos de sistemas tectônicos interpretados na área sul da Bacia do Recôncavo e norte da Bacia de Camamu: A) pré-rifte mais sinéclise; B) sequência Rifte 1; C) trato tectônico de desenvolvimento do Rifte 2; D) trato tectônico de final do Rifte 2; E) trato tectônico de desenvolvimento do Rifte 3; F) trato tectônico de final do Rifte 3; G) sequência Rifte 4; H) supersequência sin-rifte. 
A figura 11A apresenta o pacote sedimentar anterior ao rifteamento, ao qual se caracteriza por pouca variação ao longo da área estudada, onde grande parte do mapa se apresenta na cor verde, indicando espessura média de $600 \mathrm{~ms}$.

A análise das figuras 11B e 11C, indicam as maiores espessuras na região noroeste da Bacia de Camamu. Em contrapartida, se analisado apenas a região sul da Bacia do Recôncavo, também é evidente o espessamento em direção à Falha de Salvador.

O trato tectônico de desenvolvimento de rifte da sequência rifte 2 (TTDR-2, vide figura 11C) revela que um dos depocentros se encontra próximo à Falha de Salvador, e mostra um espessamento, já esperado, no sentido SE da Bacia de Camamu. O trato tectônico de final de rifte da última sequência (TTFR-2) revela que os sistemas flúvio- deltaicos característicos deste trato se instalam na parte da falha com menor rejeito, e, portanto, apresentam uma maior espessura na região da desembocadura da Baía de Todos os Santos (figura 11D).

As figuras $11 \mathrm{E}$ e $11 \mathrm{G}$ evidenciam um depocentro localizado no momento de deposição das sequências Rifte 3 e Rifte 4, junto ao último sistema de falhas, em seu trecho de maior rejeito.

Como síntese aos depósitos sin-rifte da região interpretada, foi confeccionado o mapa da figura $11 \mathrm{H}$, ao qual indica claramente o aumento de espessura na porção noroeste da Bacia de Camamu, e na parte leste da região sul da Bacia do Recôncavo. Tal análise sugere que a principal fonte de sedimentação da fase rifte se encontrava nas proximidades dos setores a noroeste da área de estudo.

\section{CONCLUSÕES}

A interpretação sísmica realizada, permitiu a identificação de discordâncias internas à seção rifte das bacias em estudo, e, portanto, a delimitação em quatro sequências de terceira ordem na fase sin-rifte (vide Figura 5), o que evidencia o caráter episódico do tectonismo sofrido pelas bacias durante o período de rifteamento.

As bacias do Recôncavo e de Camamu apresentam correlação cronoestratigráfica em seus depósitos das fases sinéclise, pré-rifte e sin-rifte, como demonstrado no mapeamento das sequências Rifte 1 , Rifte 2 e Rifte 3 (ilustrados nas seções compostas da figura 8, e nos mapas das figuras 10 e 11). Portanto, o limite estrutural entre elas, que constitui o Sistema de Falhas da Barra, não limita, estratigraficamente, os depósitos da fase rifte entre as bacias. A diferença evidente entre as duas ocorre apenas na última sequência sin-rifte mapeada (Rifte 4), e durante a fase pós-rifte, onde na Bacia do Recôncavo apresenta um caráter continental, com predominância de depósitos flúvio-deltaicos, resultando em padrões gerais progradacionais, com refletores de alta amplitude; enquanto que em Camamu, o período pós-rifteamento assume grande influência de depósitos marinhos rasos, refletindo uma transição ao sistema de margem passiva instalada na Bacia de Camamu.

A análise dos atributos sísmicos, especialmente o TecVA, foi fundamental no mapeamento estrutural do topo do embasamento e das principais falhas nas seções sísmicas (vide Figura 7A), principalmente na região do Sistema de Falhas da Barra.

A análise dos dados de poços foi fundamental na interpretação sísmica, especialmente com a aplicação da estratigrafia de sequências para bacias rifte, apresentando grande concordância com as superfícies marcadas nas seções sísmicas.

Superfícies de downlap internas às sequências Rifte 2 e Rifte 3, aliadas a interpretação dos perfis de poço, foram associadas às superfícies de máximo rifteamento das sequências (SMR-2 e SMR-3, respectivamente). Tais superfícies segmentaram cada uma das sequências nos seus tratos tectônicos de desenvolvimento (TTDR) e final de rifte (TTFR).

A superfície de início de desenvolvimento de rifte (SIDR), análogo à superfície de regressão máxima para modelos de margem passiva, foi interpretada apenas na primeira sequência da fase sin-rifte, através da análise dos dados de poço. Ou seja, não foi possível sua identificação na sismoestratigrafia por problema de resolução sísmica, considerando que na interpretação dos poços tal superfície se apresentava a no máximo cem metros acima das discordâncias, repercutindo em apenas um 
ou dois pares de refletores nos sismogramas.

Em suma, os mapas das figuras 10 e 11 permitem concluir que os depocentros caminham para sudeste (região sul da Bacia de Camamu e Falha de Salvador), onde, ao longo de sua evolução, apresentam algumas variações em suas posições na área de estudo. Um exemplo dessas variações se encontra na região norte da Bacia de Camamu, ao qual se ressalta cada vez mais um depocentro logo abaixo da ilha de Itaparica, e apresenta diferenças de profundidades ao longo do limite entre as bacias.

\section{AGRADECIMENTOS}

Os autores agradecem à GEOPARK pelo financiamento do projeto RECAMU, à FAPESB e CAPES por bolsas de Pós-Graduação em Geofísica da UFBA. M.H. agradece ao CNPq por bolsa de produtividade em pesquisa (PQ 304657/15-8).

\section{REFERÊNCIAS}

AMARAL. P.J.T. Estudo gravimétrico do arcabouço estrutural no limite entre as bacias de Camamu e Recôncavo, 2009, Rio de Janeiro. Trabalho Final de Graduação, Universidade Federal Fluminense.

CAIXETA, J.; MILHOMEM, P.; WITZKE, R.; DUPUY, I.; GONTIJO, G. Bacia de Camamu, Boletim de Geociências da Petrobrás, v. 15, n. 2, p. 455-461, 2007.

DESTRO, N.; SZATMARI, P.; ALKMIM, F.F.; MAGNAVITA, L.P. Release faults, associated structures, and their control on petroleum trends in the Recôncavo Rift, Northeast Brazil, AAPG Bulletin, v. 87, n. 7, p. 1123-1144, 2003.

FERREIRA, T.; CAIXETA, J.; LIMA, D. Controle do embasamento no rifteamento das bacias de Camamu e Almada. Boletim de Geociências da Petrobrás, 17:69-88. (2009)

GAWTHORPE, R. \& LEEDER, M. Tectono-sedimentary evolution of active extensional basins. Basin Research, v. 12, n. 3-4, p. 195-218, 2000.

HOLZ, M.; TROCCOLI, E.B.; PRADO, M. Sequence Stratigraphy of Continental Rift Basins II: An Example from the Brazilian Cretaceous Recôncavo Basin. In: Rocha; Pais; KULLBERG \& FINNEY. (Org.). STRATI 2013. Springer International Publishing, 2014, p. 15-18, 2014.

HOLZ, M.; MOREIRA, F.; TROCCOLI, E.B. A conceptual sequence stratigraphy model for continental rift successions based on the Recôncavo Basin, Cretaceous, Brazil. 2015. DOI: 10.13140/RG.2.1.3728.9846. Disp. em: <
https://www.researchgate.net/publication/280742532_STRAT I_2015_-_A_conceptual_sequence_stratigraphy_model_for_ continental_rift_successions_based_on_the_Reconcavo_Basi n_Cretaceous_Brazil>.

PAYTON, C.E. Seismic stratigraphy: applications to hydrocarbon exploration. American Association of Petroleum Geologists Memoir, v. 26, 1977.

POSAMENTIER, H.W. \& VAIL, P.R. Eustatic controls on clastic deposition. II-sequence and systems tract models. In: Sea-level changes--An integrated approach. Society of Economic Paleontologists and Mineralogists, Special Publication, v. 42, p. 125-154, 1988.

PROSSER, S. Rift-related linked depositional systems and their seismic expression. Geological Society, London, Special Publications, v. 71, n. 1, p. 35-66, 1993.

SANTOS, E.M. \& AMORIM, W.N. Princípio da sismocamada elementar e sua aplicação à Técnica de Volume de Amplitudes (TecVA), In: CONGRESSO INTERNACIONAL DA SOCIEDADE BRASILEIRA DE GEOFÍSICA, 9, 2005. Anais...

SILVA, O.B., CAIXETA, J.; MILHOMEM, P.S.; KOSIN, M. Bacia do Recôncavo. Boletim de Geociências da Petrobrás, v. 15, n. 2, p. 423-43, 2007.

Submetido em 18 de outubro de 2016 Aceito em 28 de fevereiro de 2018 